\title{
Description of Patulibacter americanus sp. nov., isolated from biological soil crusts, emended description of the genus Patulibacter Takahashi et al. 2006 and proposal of Solirubrobacterales ord. nov. and Thermoleophilales ord. nov.
}

\author{
Gundlapally S. N. Reddy and Ferran Garcia-Pichel \\ School of Life Sciences, Arizona State University, Tempe, AZ 85287-4501, USA
}

\begin{abstract}
Correspondence
Ferran Garcia-Pichel

ferran@asu.edu
\end{abstract}

\begin{abstract}
Two bacterial strains, CP153-3 and CP177-2 ${ }^{\top}$, were isolated from biological soil crusts on the Colorado Plateau, USA, and assigned to the genus Patulibacter, according to 16S rRNA gene sequence analysis and phenotypic characteristics. The strains were Gram-positive, aerobic and psychrotolerant and showed positive catalase and negative oxidase reactions. Cells were motile in young cultures, motility consisting of subtle jerking motions, but no flagella could be detected. The strains shared high 16S rRNA gene sequence similarity (99.7\%) and DNA-DNA relatedness (99\%). They contained meso-diaminopimelic acid in the cell wall, the major menaquinone was MK-7 $\left(\mathrm{H}_{2}\right)$ and the predominant fatty acids were $\mathrm{C}_{18: 1} \omega 9 \mathrm{c}$ and iso- $\mathrm{C}_{15: 0}$. A low DNA-DNA hybridization value of $20 \%$ with the type strain of the type species of the genus Patulibacter, Patulibacter minatonensis, as well as phenotypic differences, indicated that the isolates belong to a novel species, for which the name Patulibacter americanus sp. nov. is proposed. Strain CP177-2 ${ }^{\top}$ (=ATCC BAA-1038 ${ }^{\top}=$ DSM $16676^{\top}$ ) was chosen as the type strain. An emended description of the genus Patulibacter is also presented. Further, two new orders are created to accommodate several families previously classified in the order Rubrobacterales Rainey et al. 1997. The first, Solirubrobacterales ord. nov., encompasses the families Solirubrobacteraceae, Conexibacteraceae and Patulibacteraceae, and the second, Thermoleophilales ord. nov., includes the family Thermoleophilaceae.
\end{abstract}

\section{INTRODUCTION}

Biological soil crusts (BSC) are formed by living organisms and their by-products in the top millimetres to centimetres of soil (Belnap, 1993). BSCs prevent soil erosion, fix atmospheric nitrogen and recycle nutrients (Belnap \& Gardner, 1993; Belnap, 2002; Johnson et al., 2005). They are particularly common in semiarid and arid environments throughout the world (Belnap, 1994). Cultureindependent and -dependent studies on BSCs from the Colorado Plateau of North America have demonstrated the dominance of members of the Cyanobacteria, Actinobacteria, Proteobacteria and Bacteroidetes and low-

Abbreviations: BSC, biological soil crust; TEM, transmission electron microscopy.

The GenBank/EMBL/DDBJ accession numbers for the 16S rRNA gene sequences of strains CP153-3 and CP177-2 ${ }^{\top}$ are AJ871305 and AJ871306, respectively.

Comparisons of phenotypic, genotypic and chemotaxonomic properties and of fatty acid profiles are available as supplementary material with the online version of this paper.
G + C Gram-positives in these communities (Reddy \& Garcia-Pichel, 2006). Among the isolated bacteria, five novel species from the Bacteroidetes, Alphaproteobacteria and Actinobacteria have been described recently (Reddy \& Garcia-Pichel, 2005, 2007; Reddy et al., 2006, 2007). In this work, two novel isolates were subjected to polyphasic characterization, resulting in the proposal of a novel species that belongs to the class Actinobacteria (Stackebrandt et al., 1997).

The subclass Rubrobacteridae, including the order Rubrobacterales and the family Rubrobacteraceae with a single genus Rubrobacter, was described by Stackebrandt et al. (1997) in the work dedicated to a novel classification system for the actinomycete subphylum. The delineation of higher taxa within the established class Actinobacteria was proposed solely on the basis of $16 \mathrm{~S}$ rRNA gene sequencebased phylogenetic clustering and the presence of taxonspecific 16S rRNA gene signature nucleotides. Later, two species of the genus Thermoleophilum (Zarilla \& Perry, $1984,1986)$ were found to form a deep branch within the 
subclass Rubrobacteridae (Yakimov et al., 2003). Further, the genus Solirubrobacter (Singleton et al., 2003) was described within Rubrobacteridae, and the genus Conexibacter (Monciardini et al., 2003) was reported to be another deep-rooted member of this group, with the highest $16 \mathrm{~S}$ rRNA gene sequence similarity $(90 \%)$ to Thermoleophilum. The above genera were also characterized by significant variations in phenotypic characteristics such as Gram-staining, peptidoglycan composition, the respiratory quinone type and growth temperatures. Owing to the large discrepancy among these genera, Stackebrandt (2004) proposed to classify them into three different families (Conexibacteraceae, Solirubrobacteraceae and Thermoleophilaceae) under the order Rubrobacterales and emended the description of the family Rubrobacteraceae. The family Patulibacteraceae has recently been added to the order (Takahashi et al., 2006).

In the present contribution, besides describing a novel species of Patulibacter, we create two new orders, Solirubrobacterales ord. nov. and Thermoleophilales ord. nov., based on our analyses to denote the high-rank separation between the Solirubrobacterales, Thermoleophilales and Rubrobacterales. Further, the novel species differs from the generic characteristics listed for Patulibacter (Takahashi et al., 2006), mainly with respect to the respiratory quinone, and thus an emended description of the genus is proposed.

\section{METHODS}

Bacterial strains and growth conditions. Strains CP153-3 and CP177-2 ${ }^{\mathrm{T}}$ were isolated from a BSC sample collected from the Colorado Plateau as described previously (Reddy \& Garcia-Pichel, 2005). Initially, $0.5 \mathrm{~g}$ of crust sample was suspended in Ringer's solution (Reddy et al., 2006) and vortexed for $30 \mathrm{~min}$. The suspension was allowed to settle and then $100 \mu$ supernatant was plated on PGYBG11 (Reddy \& Garcia-Pichel, 2005) and incubated at room temperature for 15 days. Pink-coloured colonies were isolated, purified on 10XPGY-BG11 by streaking and maintained on the same medium.

Morphological, growth and biochemical characteristics. Cell morphology was studied using light microscopy and transmission electron microscopy (TEM). Motility was observed in wet mounts using interference contrast and confirmed by inoculation on $0.4 \%$ soft agar medium. For TEM, cells were grown in 10XPGY-BG11 medium up to late-exponential phase, mounted on Formvar-coated copper grids and negatively stained with $0.5 \%(\mathrm{w} / \mathrm{v})$ uranyl acetate. Grids were examined in TEM mode on a JEOL JEM-1010 electron microscope operated at $60 \mathrm{kV}$. Growth and biochemical characteristics, carbon assimilation and sensitivity of the cultures to antibiotics were determined as described previously (Reddy \& Garcia-Pichel, 2005; Reddy et al., 2006).

Chemotaxonomic characterization. Quantitative analysis of whole-cell fatty acids was performed after growth on tryptic soy agar (Difco) for 2 days at $25^{\circ} \mathrm{C}$. Fatty acid methyl esters were prepared according to the instructions of the Microbial Identification System (MIDI; Microbial ID, Inc.) and analysed using GC/MS. Polar lipids were extracted according to the method of Kates (1972). Approximately $100 \mathrm{mg}$ 10XPGY-BG11-grown cells was suspended in $1 \mathrm{ml} 0.3 \%$ saline in a Teflon-lined screw-capped tube. Methanol $(10 \mathrm{ml})$ was added and the mixture was heated to $100{ }^{\circ} \mathrm{C}$ for $5 \mathrm{~min}$. After cooling, $5 \mathrm{ml}$ chloroform and $3 \mathrm{ml}$ saline were added and the mixture was vortexed and centrifuged at $3500 \mathrm{~g}$ for $10 \mathrm{~min}$ to remove the debris. Five millilitres each of chloroform and saline were added to the mixture to separate the phases. The chloroform layer containing polar lipids was collected and dried. Polar lipids were analysed by one-dimensional TLC using a pre-coated silica gel plate, as described previously (Suresh et al., 2004). Cells of CP153-3 and CP177-2 $2^{\mathrm{T}}$ grown on 10XPGY-BG11 agar were scrapped off and suspended in chloroform/methanol $(2: 1)$; the suspension was vortexed and pigments were extracted. After centrifugation at 3500 $g$ for $5 \mathrm{~min}$ and evaporation of the chloroform/methanol layer, a UVvisible spectrum was recorded $(200-1200 \mathrm{~nm})$ in methanol. Peptidoglycan was prepared as described by Komagata \& Suzuki (1987). Qualitative analysis of peptidoglycan amino acids was performed by TLC using the solvent system n-butanol/acetic acid/ water (3:1:1 by vol.) and developed with ninhydrin reagent as described by Steiner et al. (1998). For quantitative analysis, peptidoglycan amino acids were analysed by the OPA (o-phthalaldehyde) method (Babu et al., 2002). Approximately $7 \mu$ l hydrolysed peptidoglycan in borate buffer was mixed with $1 \mu$ l OPA reagent (74.6 mM OPA and $94.2 \mathrm{mM}$ mercaptopropionic acid prepared in methanol and $0.4 \mathrm{M}$ sodium borate, $\mathrm{pH} 10.5$ ) in the injection loop and immediately separated on a C18 reversed-phase HPLC column. The C18 reversed-phase column was a Hypersil AA-ODS column from Agilent $(2.1 \times 200 \mathrm{~mm})$, operated at a flow rate of $0.45 \mathrm{ml}$ $\min ^{-1}$, using a linear gradient of $100 \% \mathrm{~A}($ at $t=0)$ to $40 \% \mathrm{~A}$ over $17 \mathrm{~min}$. The percentage of solvent A was then decreased to $0 \%$ at $t=18 \mathrm{~min}$. The composition of solvent A was $20 \mathrm{mM}$ sodium acetate with $0.018 \%(\mathrm{v} / \mathrm{v})$ triethylamine $(\mathrm{pH} 7.2)$ and $3 \%$ tetrahydrofuran and solvent B was $20 \mathrm{mM}$ sodium acetate ( $\mathrm{pH} 7.2)$ with $40 \%$ each of acetonitrile and methanol. Eluted amino acids were detected by a fluorescence detector set at excitation and emission wavelengths of 340 and $450 \mathrm{~nm}$, respectively. Isoprenoid quinones were extracted according to the method of Collins et al. (1977), separated on HPLC using an isocratic solvent system [methanol/isopropyl ether $(3: 1, \mathrm{v} /$ v)] and identified by MS (Tamaoka et al., 1983; Tamaoka, 1986).

G+C content, DNA-DNA hybridization and 16S rRNA gene sequencing. Isolation of DNA and determination of the $\mathrm{G}+\mathrm{C}$ content were carried out as described by Marmur (1961). A mean of two independent experiments is given. The variation between the experiments was less than $2 \%$. DNA-DNA hybridization was carried out spectroscopically as described by De Ley et al. (1970). For 16S rRNA gene sequencing, DNA was prepared using the MoBio microbial DNA isolation kit (MoBio Laboratories Inc.) and sequenced as described previously (Reddy \& Garcia-Pichel, 2005; Reddy et al., 2000).

Phylogenetic analyses. The 16S rRNA gene sequences obtained for CP153-3 and CP177-2 ${ }^{\mathrm{T}}$ were aligned with closely related sequences belonging to the class Actinobacteria using CLUSTAL W (Thompson et al., 1994). Pairwise evolutionary distances were computed using the DNADIST program with Kimura's two-parameter model (Kimura, 1980). Phylogenetic trees were constructed using four tree-making algorithms, neighbour-joining, minimum-evolution, the unweighted pair group method with arithmetic means (UPGMA) and maximumparsimony, using the MEGA 3 software package (Kumar et al., 2004). Bootstrap analysis was performed employing 1000 replicate datasets.

\section{RESULTS AND DISCUSSION}

Strains CP153-3 and CP177-2 ${ }^{\mathrm{T}}$ formed entire, pink, convex colonies. Colonies of $\mathrm{CP} 177-2^{\mathrm{T}}$ were slightly mucoid 
compared with those of CP153-3. Cells of CP153-3 and CP177- $2^{\mathrm{T}}$ consisted of short rods (bacilli to coccobacilli) that often occurred in pairs (Fig. 1). Under most conditions, cells were non-motile, but very young cultures displayed a subtle cellular jerking. While this jerking was by no means typical bacterial swimming with obvious lateral displacement, soft-agar plates confirmed that those cultures were indeed motile. No flagella were detected on negative-staining TEM inspection. Details of growth, phenotypic and chemotaxonomic characteristics of strain $\mathrm{CP} 177-2^{\mathrm{T}}$ are reported in the species description. Partial $16 \mathrm{~S}$ rRNA gene sequences of 1454 nucleotides were obtained for both CP153-3 and CP177-2 ${ }^{\mathrm{T}}$. The strains shared $99.7 \% 16 \mathrm{~S}$ rRNA gene sequence similarity and $99 \%$ DNA-DNA hybridization, indicating that the two isolates are strains of a single species; therefore, only $\mathrm{CP} 177-2^{\mathrm{T}}$ was characterized in detail.

The taxa with the most similar 16S rRNA gene sequences to these strains were Patulibacter minatonensis (Takahashi et al., 2006), Conexibacter woesei (Monciardini et al., 2003) and Solirubrobacter pauli (Singleton et al., 2003), the type strains of which shared sequence similarities of 98.7, 93.4 and $91.7 \%$, respectively. These taxa are members of different families, Patulibacteraceae (Takahashi et al., 2006), Conexibacteraceae and Solirubrobacteraceae (Stackebrandt, 2004), respectively. Detailed examination of the 16S rRNA gene sequences of strains CP153-3 and $\mathrm{CP} 177-2^{\mathrm{T}}$ was consistent with their assignment within the class Actinobacteria, since they possessed, for instance, the nucleotide A at position 906 (Stackebrandt et al., 1997), a signature nucleotide of this class (Table 1). The high sequence similarity with the 16S rRNA gene from $P$. minatonensis $\mathrm{KV}-614^{\mathrm{T}}$ and the fact that the two novel strains and $P$. minatonensis form a statistically robust, separate clade in various phylogenetic reconstruction

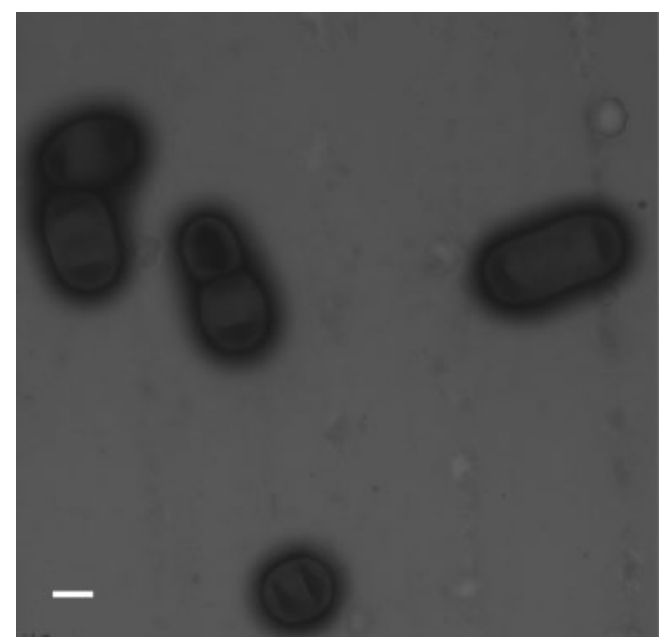

Fig. 1. Cells of strain CP177-2 ${ }^{\top}$ freshly grown in 10XPGY-BG11 medium for 2 days, negatively stained with uranyl acetate and examined in TEM. Bar, $0.5 \mu \mathrm{m}$. methods (Fig. 2) supported their assignment to the genus Patulibacter. DNA-DNA relatedness of only $20 \%$ with the type strain of Patulibacter minatonensis, JCM $12834^{\mathrm{T}}$, fell short of the suggested $70 \%$ specific threshold, indicating that the novel strains deserve separate species status (Wayne et al., 1987). The species status of CP177- $2^{\mathrm{T}}$ was further supported by the phenotypic differences from $P$. minatonensis (Table 2). For instance, cells of CP177- $2^{\mathrm{T}}$ had variable, jerking motility and colonies were pink, whereas cells of $P$. minatonensis were motile by means of flagella and colonies were pale yellow. Most importantly, the respiratory quinone present in $\mathrm{CP} 177-2^{\mathrm{T}}$ was $\mathrm{MK}-7\left(\mathrm{H}_{2}\right)$ and that of $P$. minatonensis is DMK-7, a demethylmenaquinone, which is found in only a few genera (Takahashi et al., 2006). Other differences involving growth, biochemical characteristics, sensitivity to antibiotics and utilization of carbon compounds were also apparent (Table 2).

\section{Taxonomic interpretation of the families Solirubrobacteraceae, Patulibacteraceae and Conexibacteraceae}

The members of families Solirubrobacteraceae, Patulibacteraceae and Conexibacteraceae are psychrotolerant to mesophilic and share traits such as the presence of meso-diaminopimelic acid in the cell-wall peptidoglycan, $\mathrm{C}_{18: 1} \omega 9 c$ as the major fatty acid (iso- $\mathrm{C}_{16: 0}$ and $\mathrm{C}_{18: 1} \omega 9 \mathrm{c}$ in the case of Solirubrobacteraceae) and a G $+\mathrm{C}$ content above $70 \mathrm{~mol} \%$, justifying their inclusion in a single suprageneric taxon, as suggested by the phylogenetic reconstructions. These families differ from members of the Rubrobacteraceae and Thermoleophilaceae with respect to $\mathrm{G}+\mathrm{C}$ content, peptidoglycan composition and isoprenoid quinones (Supplementary Table S1, available in IJSEM Online); other differences are listed in Supplementary Tables S1 and S2. Members of these three families form a well-defined phylogenetic clade, with a well-supported separation from the rest of Rubrobacterales Rainey et al. 1997 in all methods tested, UPGMA, neighbour-joining (Fig. 2), maximum-parsimony and minimum-evolution. Signature nucleotides of Patulibacteraceae (Takahashi et al., 2006), Conexibacteraceae and Solirubrobacteraceae (Stackebrandt, 2004) differ from those of Rubrobacteraceae Rainey et al. 1997 emend. Stackebrandt 2004 in having G-C, U-A, U-A, G-C, G-C, G-C and U-A at positions $63: 104,657: 749,681: 709,953: 1228,954: 1226$, $1051: 1207$ and 1118:1155 (seven signatures), respectively (Table 1). They also differ from members of the Thermoleophilaceae at positions 370:391, 580:776, $670: 736,681: 709,941: 1342,1118: 1155$ and $1311: 1326$ (seven signatures) (Table 1).

The above characteristics strongly justify the creation of a new order, Solirubrobacterales ord. nov., to accommodate the families Patulibacteraceae (Takahashi et al., 2006), Conexibacteraceae and Solirubrobacteraceae (Stackebrandt, 2004). Therefore, we propose the novel order Solirubrobacterales ord. nov., named after its oldest 
Table 1. Signature nucleotides of the members of the orders Solirubrobacterales ord. nov., Thermoleophilales ord. nov. and Rubrobacterales Rainey et al. 1997 emend. Reddy and Garcia-Pichel

Adapted from Stackebrandt et al. (1997), Stackebrandt (2004) and Takahashi et al. (2006). Letters in bold indicate signatures that are characteristic of the order.

\begin{tabular}{|c|c|c|c|c|c|}
\hline Position(s) & \multicolumn{3}{|c|}{ Solirubrobacterales ord. nov. } & $\begin{array}{c}\text { Rubrobacterales } \\
\text { Rubrobacteraceae }\end{array}$ & $\begin{array}{c}\text { Thermoleophilales ord. nov } \\
\text { Thermoleophilaceae }\end{array}$ \\
\hline $63: 104$ & $\mathrm{G}-\mathrm{C}$ & $\mathrm{G}-\mathrm{C}$ & $\mathrm{G}-\mathrm{C}$ & C-G & $\mathrm{G}-\mathrm{C}$ \\
\hline $70: 98$ & $\mathrm{G}-\mathrm{C}$ & $\mathrm{G}-\mathrm{C}$ & $\mathrm{G}-\mathrm{C}$ & A-U & $\mathrm{G}-\mathrm{C}$ \\
\hline $127: 234$ & $\mathrm{G}-\mathrm{C}$ & $\mathrm{G}-\mathrm{C}$ & $\mathrm{G}-\mathrm{C}$ & $\mathrm{G}-\mathrm{C}$ & $\mathrm{G}-\mathrm{C}$ \\
\hline $291: 309$ & $\mathrm{U}-\mathrm{A}$ & $\mathrm{U}-\mathrm{A}$ & $\mathrm{U}-\mathrm{A}$ & $\mathrm{U}-\mathrm{A}$ & $\mathrm{U}-\mathrm{A}$ \\
\hline $370: 391$ & $\mathrm{C}-\mathrm{G}$ & $\mathrm{C}-\mathrm{G}$ & $\mathrm{C}-\mathrm{G}$ & $\mathrm{C}-\mathrm{G}$ & $\mathrm{G}-\mathrm{C}$ \\
\hline $408: 434$ & $\mathrm{G}-\mathrm{C}$ & $\mathrm{A}-\mathrm{U}$ & $\mathrm{G}-\mathrm{C}$ & $\mathrm{G}-\mathrm{C}$ & $\mathrm{G}-\mathrm{C}$ \\
\hline $580: 776$ & $\mathrm{U}-\mathrm{A}$ & $\mathrm{U}-\mathrm{A}$ & $\mathrm{U}-\mathrm{A}$ & $\mathrm{U}-\mathrm{A}$ & C-G \\
\hline $590: 649$ & $\mathrm{U}-\mathrm{A}$ & $\mathrm{U}-\mathrm{A}$ & $\mathrm{C}-\mathrm{G}$ & $\mathrm{C}-\mathrm{G}$ & $\mathrm{C}-\mathrm{G}$ \\
\hline $823: 877$ & $\mathrm{~A}-\mathrm{U}$ & $\mathrm{G}-\mathrm{C}$ & $\mathrm{G}-\mathrm{C}$ & $\mathrm{G}-\mathrm{C}$ & $\mathrm{G}-\mathrm{C}$ \\
\hline 906 & $\mathrm{~A}$ & $\mathrm{~A}$ & $\mathrm{~A}$ & $\mathrm{~A}$ & $\mathrm{~A}$ \\
\hline $941: 1342$ & $\mathrm{~A}-\mathrm{U}$ & $\mathrm{A}-\mathrm{U}$ & $\mathrm{A}-\mathrm{U}$ & $\mathrm{A}-\mathrm{U}$ & G-C \\
\hline $953: 1228$ & $\mathrm{G}-\mathrm{C}$ & $\mathrm{G}-\mathrm{C}$ & $\mathrm{G}-\mathrm{C}$ & U-A & $\mathrm{G}-\mathrm{C}$ \\
\hline $954: 1226$ & $\mathrm{G}-\mathrm{C}$ & $\mathrm{G}-\mathrm{C}$ & $\mathrm{G}-\mathrm{C}$ & C-G & $\mathrm{G}-\mathrm{C}$ \\
\hline $955: 1225$ & $\mathrm{U}-\mathrm{A}$ & $\mathrm{U}-\mathrm{A}$ & $\mathrm{U}-\mathrm{A}$ & $\mathrm{U}-\mathrm{A}$ & $\mathrm{U}-\mathrm{A}$ \\
\hline $999: 1041$ & $\mathrm{U}-\mathrm{A}$ & $\mathrm{G}-\mathrm{U}$ & $\mathrm{U}-\mathrm{A}$ & $\mathrm{U}-\mathrm{A}$ & A-U \\
\hline $1051: 1207$ & $\mathrm{G}-\mathrm{C}$ & $\mathrm{G}-\mathrm{C}$ & $\mathrm{G}-\mathrm{C}$ & C-G & $\mathrm{G}-\mathrm{C}$ \\
\hline $1115: 1185$ & $\mathrm{C}-\mathrm{G}$ & $\mathrm{C}-\mathrm{G}$ & $\mathrm{C}-\mathrm{G}$ & $\mathrm{C}-\mathrm{G}$ & $\mathrm{C}-\mathrm{G}$ \\
\hline $1118: 1155$ & U-A & U-A & U-A & $\mathrm{C}-\mathrm{G}$ & $\mathrm{C}-\mathrm{G}$ \\
\hline $1311: 1326$ & $\mathrm{~A}-\mathrm{U}$ & $\mathrm{A}-\mathrm{U}$ & $\mathrm{A}-\mathrm{U}$ & $\mathrm{A}-\mathrm{U}$ & G-C \\
\hline
\end{tabular}

standing genus. The creation of the Solirubrobacterales is further justified by the long evolutionary distances observed between the species of Solirubrobacterales and Rubrobacterales Rainey et al. 1997 emend. Reddy and Garcia-Pichel (84.5-92\% 16S rRNA gene sequence similarity), which are comparable to the distances that separate other orders, such as the Actinomycetales and Bifidobacteriales (81-89\%).

\section{Taxonomic interpretation of the genus Thermoleophilum}

The members of the genus Thermoleophilum are nonmotile rods and stain Gram-negative (although TEM displayed a series of layers characteristic of Gram-positive bacteria; Yakimov et al., 2003), and colonies are nonpigmented. They are thermophilic and contain mesodiaminopimelic acid in the peptidoglycan (Supplementary Table S1). Presently, the genus has two species, Thermoleophilum album (Zarilla \& Perry, 1984) and Thermoleophilum minutum (Zarilla \& Perry, 1986;
Yakimov et al., 2003). An earlier comparative analysis based on 16S rRNA gene sequences placed the genus under group 2 of the subclass Rubrobacteridae (Yakimov et al., 2003). More recently, Stackebrandt (2004) created the family Thermoleophilaceae to accommodate the two species within the order Rubrobacterales. In the present analyses, all of the phylogenetic algorithms indicated that the genus Thermoleophilum formed a deeply branched, robust cluster of its own (Fig. 2) and a sister rather than a subordinate taxon to the Rubrobacterales Rainey et al. 1997. Further, they showed eight signature nucleotides that differed from Solirubrobacterales ord. nov. and 15 signatures at positions $52: 359,63: 104,139: 224,144: 178,370: 391,580: 776$, $600: 638, \quad 657: 749, \quad 670: 736, \quad 941: 1342, \quad 953: 1228$, $954: 1226,999: 1041,1051: 1207$ and $1311: 1326$ that differed from the rest of Rubrobacterales Rainey et al. 1997 emend. Reddy and Garcia-Pichel (Table 1). Thus, the differences in signature nucleotides and the phylogenetic reconstructions clearly support the creation of a higher taxonomic rank for this family, for which the name Thermoleophilales ord. nov. is proposed. Although not 


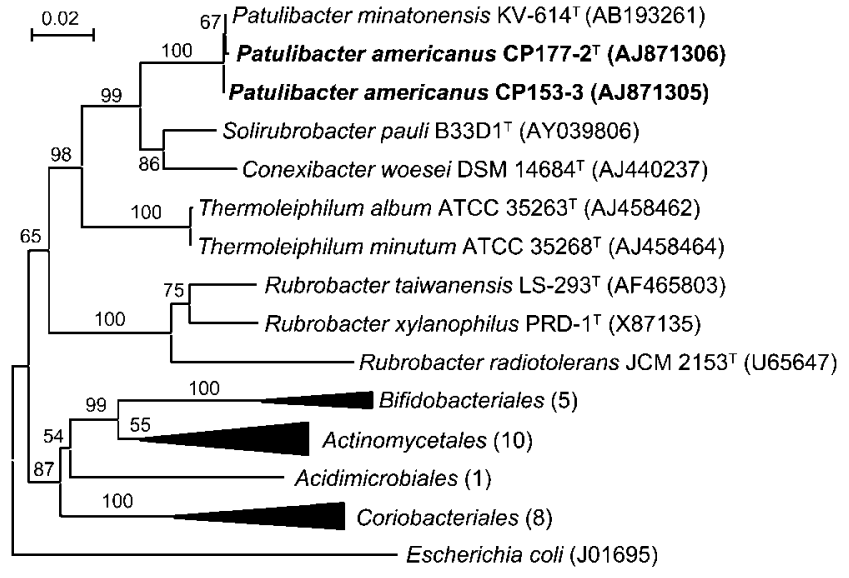

Fig. 2. Neighbour-joining tree based on 16S rRNA gene sequences showing the phylogenetic relationships between strain CP177-2 ${ }^{\top}$ and related reference micro-organisms of the class Actinobacteria. Bootstrap values (expressed as percentages of 1000 replications) greater than $40 \%$ are indicated at nodes. Some clades have been collapsed into triangles for clarity, with the number of sequences used in each indicated in parentheses. Bar, 0.02 substitutions per nucleotide position.

much information is available about the phenotypic characteristics of the species of Thermoleophilum, traits such as their thermophilic nature, Gram-negative staining reaction (although electron microscopy of the cell wall showed morphology typical of Gram-positive bacteria) and lack of pigmentation support the delineation of Thermoleophilales ord. nov. from Solirubrobacterales ord. nov. (Supplementary Table S1). Members of the order Thermoleophilales ord. nov. differ from members of Rubrobacterales Rainey et al., 1997 emend. Reddy and Garcia-Pichel with respect to pigmentation, Gram-staining and peptidoglycan (Supplementary Table S1).

\section{Emended description of the order Rubrobacterales Rainey et al. 1997}

Contains the family Rubrobacteraceae. Known members are thermophilic, non-motile rods-cocci that stain Grampositive and contain L-Lys as the diamino acid at position 3 of the peptidoglycan and MK-8 as the predominant menaquinone. Further characterized by the presence of $16 \mathrm{~S}$ rRNA gene sequence signatures $\mathrm{C}-\mathrm{G}, \mathrm{A}-\mathrm{U}, \mathrm{U}-\mathrm{A}, \mathrm{G}-\mathrm{C}$, G-C, U-A, C-G and C- G at positions $63: 104,70: 98$, $139: 224,144: 178,657: 749,953: 1228,954: 1226$ and $1051: 1207$, respectively. The type genus is Rubrobacter.

\section{Description of Solirubrobacterales ord. nov.}

Solirubrobacterales (So'li.ru.bro.bac'te.ra'les. N.L. masc. n. Solirubrobacter type genus of the order; suff. -ales ending denoting an order; N.L. fem. pl. n. Solirubrobacterales the Solirubrobacter order).
Contains the families Solirubrobacteraceae, Conexibacteraceae and Patulibacteraceae. Members of the order are Gram-positive, mesophilic, sometimes psychrotolerant and contain meso-diaminopimelic acid as the diamino acid at position 3 of the peptidoglycan. Further characterized by the presence of $16 \mathrm{~S}$ rRNA gene sequence signature nucleotides $\mathrm{G}-\mathrm{C}, \mathrm{G}-\mathrm{C}, \mathrm{C}-\mathrm{G}, \mathrm{U}-\mathrm{A}, \mathrm{U}-\mathrm{A}, \mathrm{A}-\mathrm{U}, \mathrm{U}-\mathrm{A}, \mathrm{A}-$ $\mathrm{U}, \mathrm{G}-\mathrm{C}, \mathrm{G}-\mathrm{C}, \mathrm{G}-\mathrm{C}, \mathrm{U}-\mathrm{A}$ and $\mathrm{A}-\mathrm{U}$ at positions $63: 104$, $70: 98,370: 391,580: 776,657: 749,670: 736,681: 709$, $941: 1342,953: 1228,954: 1226,1051: 1207,1118: 1155$ and 1311:1326, respectively. Differ from the Rubrobacterales Rainey et al. 1997 emend. Reddy and Garcia-Pichel in containing U-A at positions 681:709 and $1118: 1155$. Other differences in signature nucleotides from Rubrobacterales Rainey et al. 1997 (Stackebrandt, 2004) and Thermoleophilales ord. nov. are listed in Table 1. The type genus is Solirubrobacter.

\section{Description of Thermoleophilales ord. nov.}

Thermoleophilales (Ther.mo'le.o.phi.la'les. N.L. neut. n. Thermoleophilum type genus of the order; suff. -ales ending denoting an order; N.L. fem. pl. n. Thermoleophilales the Thermoleophilum order).

Contains the family Thermoleophilaceae. Members stain Gram-negative (TEM demonstrates a series of layers typical of Gram-positive bacteria), are thermophilic and contain meso-diaminopimelic acid as the diamino acid in the peptidoglycan. The order is further characterized by the presence of $16 \mathrm{~S}$ rRNA gene sequence signature nucleotides at various positions as listed in Table 1. Thermoleophilum is the type genus.

\section{Emended description of the genus Patulibacter Takahashi et al. 2006}

Patulibacter (Pa.tu'li.bac'ter. L. adj. patulus spreading; N.L. masc. n. bacter from Gr. n. baktron a rod; N.L. masc. n. Patulibacter rod with spreading growth).

Cells are Gram-positive, non-endospore-forming, rodshaped, aerobic, catalase-positive and oxidase-negative; motility is variable. Cell-wall peptidoglycan contains mesodiaminopimelic acid as diamino acid along with alanine and glutamic acid. The fatty acid profile is dominated by anteiso- $\mathrm{C}_{15: 0}$, anteiso- $\mathrm{C}_{17: 0}$ and $\mathrm{C}_{18: 1} \omega 9 \mathrm{c}$. Mycolic acids are absent. The predominant isoprenoid quinone is DMK7 or MK-7 $\left(\mathrm{H}_{2}\right)$. The DNA G $+\mathrm{C}$ content is approximately $72 \mathrm{~mol} \%$. The type species is Patulibacter minatonensis.

\section{Description of Patulibacter americanus sp. nov.}

Patulibacter americanus (a.me.ri.ca'nus. N.L. masc. adj. americanus American, referring to the isolation of the type strain from the Colorado Plateau).

Colonies are pink-pigmented, convex, entire, smooth and slightly mucoid. Cells are short rods that stain Gram- 
Table 2. Comparison of phenotypic characteristics of strains CP177-2 ${ }^{\top}$ and $\mathrm{CP} 153-3$ and $P$. minatonensis JCM $12834^{\top}$

Data for P. minatonensis JCM $12834^{\mathrm{T}}$ were taken from Takahashi et al. (2006). -, Negative; +, positive; ND, no data available; s, sensitive; R, resistant; MK, menaquinone; DMK, demethylmenaquinone.

\begin{tabular}{|c|c|c|c|}
\hline Characteristic & CP153-3 & $\mathrm{CP} 177-2^{\mathrm{T}}$ & P. minatonensis $\mathrm{JCM} 12834^{\mathrm{T}}$ \\
\hline Colony colour & Pink & Pink & Pale-yellow \\
\hline Motility & Variable (jerking) & Variable (jerking) & Motile by flagella \\
\hline Growth temperature range $\left({ }^{\circ} \mathrm{C}\right)$ & $5-30$ & $10-30$ & $16-28$ \\
\hline Lipase & + & + & - \\
\hline Phosphatase & + & - & + \\
\hline \multicolumn{4}{|c|}{ Sensitivity to antibiotics ( $\mu$ g per disc) } \\
\hline Aztreonam (30) & S & $\mathrm{R}$ & $\mathrm{R}$ \\
\hline Chloramphenicol (30) & $\mathrm{R}$ & s & s \\
\hline Cephalothin (30) & $\mathrm{R}$ & s & $\mathrm{ND}$ \\
\hline Erythromycin (2) & s & $\mathrm{R}$ & s \\
\hline Sulfisoxazole (300) & $\mathrm{R}$ & s & $\mathrm{ND}$ \\
\hline Tetracycline (30) & $\mathrm{R}$ & s & s \\
\hline \multicolumn{4}{|l|}{ Utilization of carbon compounds } \\
\hline Arabinose & - & - & + \\
\hline Cellobiose & - & - & + \\
\hline Glucose & - & + & $\mathrm{ND}$ \\
\hline Galactose & - & - & + \\
\hline Inositol & - & - & + \\
\hline Maltose & - & + & + \\
\hline Mannitol & - & - & + \\
\hline Mannose & - & - & + \\
\hline Rhamnose & - & - & + \\
\hline Ribose & - & - & + \\
\hline Sucrose & + & + & - \\
\hline Sorbitol & - & + & - \\
\hline Xylose & - & + & + \\
\hline Arginine & - & + & $\mathrm{ND}$ \\
\hline Serine & - & - & + \\
\hline Menaquinone & $\mathrm{MK}-7\left(\mathrm{H}_{2}\right)$ & $\mathrm{MK}-7\left(\mathrm{H}_{2}\right)$ & DMK-7 \\
\hline
\end{tabular}

positive. Motility is variable and, when present, occurs through jerking cellular motions. Growth is observed at $10-30{ }^{\circ} \mathrm{C}$ (but not at $37{ }^{\circ} \mathrm{C}$ ), with an optimum at $25^{\circ} \mathrm{C}$, and at $\mathrm{pH} 5-9$, with an optimum at $\mathrm{pH}$ 7. Tolerates $\mathrm{NaCl}$ concentrations of less than $3 \%$. Tests positive for catalase and lipase but negative for oxidase, urease, $\beta$-galactosidase, gelatinase, phenylalanine deaminase and arginine, lysine and ornithine decarboxylases. Also negative for the methyl red test, Voges-Proskauer reaction, indole production and growth on Simmons' citrate. Does not hydrolyse casein, cellulose, aesculin or starch and can not produce $\mathrm{H}_{2} \mathrm{~S}$ or reduce nitrate to nitrite. Utilizes D-glucose, inulin, Dlaevulose, melibiose and sucrose as sole carbon sources. Can not grow on acetate, citrate, dextran, ethanolamine, Dfructose, glycerol, pyruvate, succinate, L-alanine, L-aspartic acid, L-cysteine, L-glycine, L-glutamine, L-glutamic acid, Lhistidine, L-leucine, L-lysine, L-phenylalanine, L-tryptophan, L-tyrosine, adenine, cytosine, guanine, thymidine, nicotinic acid, tartaric acid, adonitol, dulcitol, fumaric acid, lactose, lactic acid, raffinose, L-sorbose, trehalose, Lasparagine, L-isoleucine, L-methionine, L-proline, L-threonine, L-valine, oxalate, phenanthrene or indole. Sensitive to
( $\mu \mathrm{g}$ per disc unless indicated) bacitracin $(10 \mathrm{U})$, ceftriaxone (30), doxycycline (30), gentamicin (10), novobiocin (30), polymyxin B (300 U), rifampicin (30), streptomycin (10) and vancomycin (30) and resistant to azithromycin (50), carbenicillin (100), ciprofloxacin (5), colistin (10), ethambutol (50), nitrofurantoin (150), penicillin (10 U), sulfathiazole (300) and trimethoprim (5). Additional characteristics are listed in Table 2. Cell-wall peptidoglycan contains meso-diaminopimelic acid as the diamino acid with alanine and glutamic acid in the ratio of $1: 2: 1$ and MK- $7\left(\mathrm{H}_{2}\right)$ as the sole respiratory quinone. Methanol extracts exhibit absorption maxima at 327, 395, 434, 459 and $488 \mathrm{~nm}$. Fatty acids are listed in Supplementary Table S2. Polar lipids include unknown phospholipid 1, unknown phospholipid 2, which co-migrated with phosphatidylinositol, and phosphatidylcholine, phosphatidylglycerol and diphosphatidylglycerol (cardiolipin). The $\mathrm{G}+\mathrm{C}$ content of the DNA of the type strain is $72 \mathrm{~mol} \%$.

The type strain is CP177- $2^{\mathrm{T}}$ (=ATCC BAA- $1038^{\mathrm{T}}=\mathrm{DSM}$ $16766^{\mathrm{T}}$ ), isolated from BSC from the Colorado Plateau, USA. Strain CP153-3 (=ATCC BAA-1037), isolated from 
the same source, is a reference strain. Phenotypic characteristics of the type strain are the same as those described above for the species; differences between strains CP177-2 ${ }^{\mathrm{T}}$ and CP153-3 are listed in Table 2.

\section{Note added in preparation}

While this article was under review, another species of the genus Solirubrobacter, Solirubrobacter soli, was described (Kim et al., 2007).

\section{ACKNOWLEDGEMENTS}

The research was funded by the National Science Foundation Biotic Surveys and inventories grant 0206711 to F. G. P. The authors also thank the editor for her keen reviewing of our paper and also editing part of the text.

\section{REFERENCES}

Babu, S. S. V., Shareef, M. M., Shetty, A. P. K. \& Shetty, K. T. (2002). HPLC method for amino acids profile in biological fluids and inborn metabolic disorders of aminoacidopathies. Indian J Clin Biochem 17, 7-26.

Belnap, J. (1993). Recovery rates of cryptobiotic crusts: inoculant use and assessment methods. Great Basin Nat 53, 89-95.

Belnap, J. (1994). Potential role of cryptobiotic soil crust in semiarid rangelands. In Proceedings - Ecology and Management of Annual Rangelands, pp. 179-185. Edited by S. B. Monsen \& S. G. Kitchen. Ogden, UT: USDA Forest Service, Intermountain Research Station.

Belnap, J. (2002). Impacts of off road vehicles on nitrogen cycles in biological soil crusts: resistance in different US deserts. J Arid Environ 52, 155-165.

Belnap, J. \& Gardner, J. S. (1993). Soil microstructure in soils of the Colorado Plateau: the role of the cyanobacterium Microcoleus vaginatus. Great Basin Nat 53, 40-47.

Collins, M. D., Pirouz, T., Goodfellow, M. \& Minnikin, D. E. (1977). Distribution of menaquinones in actinomycetes and corynebacteria. $J$ Gen Microbiol 100, 221-230.

De Ley, J., Cattoir, H. \& Reynaerts, A. (1970). The quantitative measurement of DNA hybridization from renaturation rates. Eur Biochem 12, 133-142.

Johnson, S. L., Budinoff, C., Belnap, J. \& Garcia-Pichel, F. (2005). Relevance of ammonium oxidation within biological soil crust communities. Environ Microbiol 7, 1-12.

Kates, M. (1972). Techniques of Lipidology: Isolation, Analysis and Identification of Lipids. Edited by T. S. Work \& E. Work. New York: Elsevier.

Kim, M. K., Na, J. R., Lee, T. H., Im, W. T., Soung, N. K. \& Yang, D. C. (2007). Solirubrobacter soli sp. nov., isolated from soil of a ginseng field. Int J Syst Evol Microbiol 57, 1453-1455.

Kimura, M. (1980). A simple method for estimating evolutionary rates of base substitutions through comparative studies of nucleotide sequences. J Mol Evol 16, 111-120.

Komagata, K. \& Suzuki, K. (1987). Lipid and cell-wall analysis in bacterial systematics. Methods Microbiol 19, 161-207.

Kumar, S., Tamura, K. \& Nei, M. (2004). MEGA3: integrated software for molecular evolutionary genetics analysis and sequence alignment. Brief Bioinform 5, 150-163.
Marmur, J. (1961). A procedure for the isolation of deoxyribonucleic acid from microorganisms. J Mol Biol 3, 208-218.

Monciardini, P., Cavaletti, L., Schumann, P., Rohde, M. \& Donadio, S. (2003). Conexibacter woesei gen. nov., sp. nov., a novel representative of a deep evolutionary line of descent within the class Actinobacteria. Int J Syst Evol Microbiol 53, 569-576.

Reddy, G. S. N. \& Garcia-Pichel, F. (2005). Dyadobacter crusticola sp. nov., from biological soil crusts in the Colorado Plateau, USA, and an emended description of the genus Dyadobacter Chelius and Triplett 2000. Int J Syst Evol Microbiol 55, 1295-1299.

Reddy, G. S. N. \& Garcia-Pichel, F. (2006). The community and phylogenetic diversity of biological soil crusts in the Colorado Plateau studied by molecular fingerprinting and intensive cultivation. Microb Ecol 52, 345-357.

Reddy, G. S. N. \& Garcia-Pichel, F. (2007). Sphingomonas mucosissima sp. nov. and Sphingomonas dessicabilis sp. nov., isolated from biological soil crusts in the Colorado Plateau, USA. Int J Syst Evol Microbiol 57, 1028-1034.

Reddy, G. S. N., Aggarwal, R. K., Matsumoto, G. I. \& Shivaji, S. (2000). Arthrobacter flavus sp. nov., a psychrophilic bacterium isolate from a pond in McMurdo Dry Valley, Antarctica. Int J Syst Evol Microbiol 50, 1553-1561.

Reddy, G. S. N., Nagy, M. \& Garcia-Pichel, F. (2006). Belnapia moabensis gen. nov., sp. nov., an alphaproteobacterium from biological soil crusts in the Colorado Plateau, USA. Int J Syst Evol Microbiol 56, 51-58.

Reddy, G. S. N., Potrafka, R. \& Garcia-Pichel, F. (2007). Modestobacter versicolor sp. nov., an actinobacterium from biological soil crusts that produces melanins under oligotrophy, with emended descriptions of the genus Modestobacter and Modestobacter multiseptatus Mevs et al. 2000. Int J Syst Evol Microbiol 57, 2014-2020.

Singleton, D. R., Furlong, M. A., Peacock, A. D., White, D. C., Coleman, D. C. \& Whitman, W. B. (2003). Solirubrobacter pauli gen. nov., sp. nov., a mesophilic bacterium within the Rubrobacteridae related to common soil clones. Int J Syst Evol Microbiol 53, 485-490.

Stackebrandt, E. (2004). Will we ever understand? The undescribable diversity of the prokaryotes. Acta Microbiol Immunol Hung 51, 449462.

Stackebrandt, E., Rainey, F. A. \& Ward-Rainey, N. L. (1997). Proposal for a new hierarchic classification system, Actinobacteria classis nov. Int J Syst Bacteriol 47, 479-491.

Steiner, R. A., Fried, B. \& Sherma, J. (1998). HPTLC determination of amino acids in snail-conditioned water from Biomphalaria glabrata, two strains of Helisoma trivolis, and Lymnaea elodes. J Liq Chromatogr Relat Technol 21, 427-432.

Suresh, K., Reddy, G. S. N., Sengupta, S. \& Shivaji, S. (2004). Deinococcus indicus sp. nov., an arsenic-resistant bacterium from an aquifer in West Bengal, India. Int J Syst Evol Microbiol 54, 457-461.

Takahashi, Y., Matsumoto, A., Morisaki, K. \& Ōmura, S. (2006). Patulibacter minatonensis gen. nov., sp. nov., a novel actinobacterium isolated using an agar medium supplemented with superoxide dismutase, and proposal of Patulibacteraceae fam. nov. Int J Syst Evol Microbiol 56, 401-406.

Tamaoka, J. (1986). Analysis of bacterial menaquinone mixtures by reverse-phase high-performance liquid chromatography. Methods Enzymol 123, 251-256.

Tamaoka, J., Katayama-Fujimura, Y. \& Kuraishi, H. (1983). Analysis of bacterial menaquinone mixture by high performance liquid chromatography. J Appl Bacteriol 54, 31-36.

Thompson, J. D., Higgins, D. G. \& Gibson, T. J. (1994). Clustal W: improving the sensitivity of progressive multiple sequence alignment 
through sequence weighting, position-specific gap penalties and weight matrix choice. Nucleic Acids Res 22, 4673-4680.

Wayne, L. G., Brenner, D. J., Colwell, R. R., Grimont, P. A. D., Kandler, O., Krichevsky, M. I., Moore, L. H., Moore, W. E. C., Murray, R. G. E. \& other authors (1987). International Committee on Systematic Bacteriology. Report of the ad hoc committee on reconciliation of approaches to bacterial systematics. Int J Syst Bacteriol 37, 463-464.

Yakimov, M. M., Lunsdorf, H. \& Golyshin, P. N. (2003). Thermoleophilum album and Thermoleophilum minutum are cultur- able representatives of group 2 of the Rubrobacteridae (Actinobacteria). Int J Syst Evol Microbiol 53, 377-380.

Zarilla, K. A. \& Perry, J. J. (1984). Thermoleophilum album gen. nov. and sp. nov., a bacterium obligate for thermophily and n-alkane substrates. Arch Microbiol 137, 286-290.

Zarilla, K. A. \& Perry, J. J. (1986). Deoxyribonucleic acid homology and other comparisons among obligately thermophilic hydrocarbonoclastic bacteria, with a proposal for Thermoleophilum minutum sp. nov. Int J Syst Bacteriol 36, 13-16. 